\title{
Mailed Fecal Immunochemical Tests Plus Educational Materials to Improve Colon Cancer Screening Rates in Iowa Research Network (IRENE) Practices
}

\author{
Barcey T. Levy, PhD, MD, Jeanette M. Daly, PhD, RN, Yinghui Xu, MS, \\ and John W. Ely, MD, MSPH
}

Introduction: Only about half of all eligible Americans have been screened for colorectal cancer (CRC). The objective of this study was to test whether mailed educational materials and a fecal immunochemical test (FIT), with or without a scripted telephone reminder, led to FIT testing. In addition, we compared changes in attitudes toward, readiness for, and barriers to screening from baseline to follow-up after education about screening.

Methods: Subjects due for CRC screening were recruited from 16 Iowa Research Network family physician offices. Half of the subjects were randomized to receive mailed written and DVD educational materials, along with a FIT, either with or without a telephone call designed to encourage screening and address barriers. Subjects completed surveys regarding their attitudes and readiness for CRC screening at baseline and after education about screening. The main outcome was whether the subject completed FIT testing.

Results: A total of 373 individuals received educational materials (including a FIT) and 231 (62\%) returned a posteducation survey. The mean age was 61.2 years; $52 \%$ were women, $99 \%$ were white, $39 \%$ had a high school education or less, $39 \%$ had a total family income of less than $\$ \mathbf{4 0 , 0 0 0}$, and $\mathbf{7 \%}$ had no insurance. The written materials were read by $82 \%$, understood by $91 \%$ (of those who read them), and $82 \%$ felt their knowledge was increased. The DVD was viewed by $67 \%$, understood by $94 \%$ of those who viewed it, and $86 \%$ felt the DVD increased their knowledge. Compared with baseline, individuals reported being significantly more likely to bring up CRC screening at their next doctor's visit $(P<.0001)$ and being more likely to be tested for CRC in the next 6 months $(P<.0001)$. Comparing baseline with follow-up, summary attitude scores improved $(P<.0001)$, readiness scores improved $(P<.0001)$, and there were fewer barriers $(P=$ .034 , Wilcoxon signed rank). The FIT return rate increased from $0 \%$ to $45.2 \%$ in the education alone group and from $0 \%$ to $48.7 \%$ for the group receiving education plus the telephone call $(P<.0001$ for each group individually and overall when compared with Medicare beneficiaries in Iowa).

Conclusions: Mailing FIT kits with easy-to-understand educational materials improved attitudes toward screening and dramatically increased CRC screening rates among patients who were due for screening in a practice-based research network. A telephone call addressing barriers to screening did not result in increased FIT testing compared with mailed education alone. (J Am Board Fam Med 2012;25:73-82.)

Keywords: Cancer Screening, Colorectal Cancer, Health Education, Practice-based Research, Randomized Clinical Trials, Rural Health

It has been estimated that $50 \%$ to $80 \%$ of colorectal cancer (CRC) cases are preventable or treatable if caught early. ${ }^{1-4}$ Several national organizations have guidelines for CRC screening. ${ }^{5-7}$ However,

This article was externally peer reviewed.

Submitted 15 February 2011; revised 21 July 2011; accepted 22 August 2011.

From the Department of Family Medicine (BTL, JMD, YX, JWE) and the Department of Epidemiology (BTL), Roy J. and Lucille A. Carver College of Medicine and College of Public Health, University of Iowa, Iowa City. although screening rates are increasing, only about half to two-thirds of eligible Americans have been tested for CRC. ${ }^{3,8-10}$ The focus of this study was to test an intervention to improve screening rates by mailing an educational packet designed to motivate patients and facilitate their screening. ${ }^{11-14}$

Funding: We gratefully acknowledge the support of the American Cancer Society (Research Scholar Grant targeted, 08-148-01, CPPB, BTL) and the University of Iowa, Department of Family Medicine, Iowa City. 
In this study, we randomized subjects from 16 rural Iowa Research Network (IRENE) practices who were eligible for CRC screening (based on their self-report) to 1 of 4 groups. Half of the subjects were randomized to receive educational materials and a fecal immunochemical test (FIT) kit with or without a telephone call to encourage CRC screening. Many patients prefer a fecal test that can be completed at home compared with colonoscopy. ${ }^{15-17}$ This report addresses 2 of the 4 groups (half of the total subjects) that received the educational materials. The primary outcome variable was return of the FIT, but we also assessed whether educational materials were viewed and understood, as well as any change in attitudes toward CRC screening, readiness for screening, and barriers to screening at baseline and following the mailed educational intervention. The purpose of this study was to compare changes in attitudes toward, readiness for, and barriers to screening from baseline to follow-up after education, as well as return of the FIT, in the 2 groups randomized to the educational intervention.

\section{Methods}

\section{Recruitment of Practices}

Fifty-eight family physician practices provided a letter of support for the original grant submission. Of these 58 practices, 27 were located in rural counties with a median per capita income level below the state average. In 2008, we randomly selected 16 practices from these 27 to participate in the study. One practice was unable to participate when the study was initiated so another practice was randomly selected. Practices in counties with a per capita income below the state average in order were selected to increase the likelihood of enrolling individuals with a low socioeconomic status to participate in the study.

One of 2 investigators (JE or BTL) visited each participating practice and presented information about the study, obtained the informed consent of participating physicians, and had the physicians complete a written questionnaire about their attitudes toward and practices related to CRC screen-

Trial registration: clinicaltrials.gov identifier: NCT01477814. Conflict of interest: none declared.

Corresponding author: Barcey T. Levy, University of Iowa, 200 Hawkins Drive, 01292 E. Pomerantz FamilyPavilion, Iowa City, IA 52242 (E-mail: barcey-levy@uiowa.edu). ing. In addition, after completion of the questionnaire, physicians received a copy of the CRC screening guidelines, as well as a pocket card that summarized the guidelines and briefly described each CRC screening modality. Each practice chose a study coordinator who completed human subjects' training through the online Collaborative Institutional Training Initiative program. ${ }^{18}$

\section{Recruitment of Subjects Within Practices}

The University of Iowa study coordinator (JD) worked with each practice to obtain a list of their active patients aged 52 to 79 years. Fifty-two years was chosen as the minimum age to ensure individuals had time to be screened once they turned 50 . Seventy-nine years was chosen as the maximum age because other health issues often make screening less relevant above that age. From these lists, we randomly selected 530 individuals so that half were men and half were women. All but 4 practices had more than 530 individuals aged 52 to 79 years. A total of 8372 subjects were invited to participate over the time period of December 3, 2008, to April 16,2010 . Subjects were recruited using a modified Dillman technique, ${ }^{19}$ as described in the companion article in this issue. ${ }^{20}$ Subjects received $\$ 20$ for completion of the baseline questionnaire and $\$ 10$ for completion of the educational assessment questionnaire. All mailings were done using medical office stationery and were signed by the providers from each office and the principal investigator (PI; BTL) for the study. From the 8372 mailings, a total of 743 patients $(9 \%)$ were eligible and returned a baseline survey and an informed consent document.

\section{Baseline Questionnaire}

The questionnaire was developed by the PI (BTL) and contained questions about each main method of CRC screening (fecal occult cards, FIT, flexible sigmoidoscopy, barium enema, and colonoscopy), how recently the test was completed (using the time frames in published guidelines), and why the test was done; family history of CRC; personal history of ulcerative colitis or Crohn disease; whether a doctor or a nurse has ever discussed CRC screening with the patient; whether their physician has ever recommended that the patient undergo CRC screening; whether the patient's doctor has ever recommended a CRC test for symptoms; a series of questions about CRC screening readiness, atti- 
tudes, and barriers; and a demographic section. The questionnaire has been tested extensively with more than 500 participants in a previous study. ${ }^{9,21}$ Although developed independently of Vernon et al' $\mathrm{s}^{22}$ instrument, many of the questions designed to ascertain screening status were very similar to the questions developed by Vernon et al. The subject's answers on the baseline questionnaire were used to determine eligibility for the study. Subjects were considered ineligible if they self-reported being up to date with CRC screening by any method (fecal occult or FIT within the past year, barium enema or flexible sigmoidoscopy within the past 5 years, or colonoscopy within the past 10 years). ${ }^{5-7}$

\section{Randomization of Subjects}

Eligible subjects were randomized with equal chance to 1 of 4 groups. A total of 373 subjects were randomized to receive educational materials containing a FIT (described below), and these patients comprised the 2 groups reported on in this article.

\section{Educational Materials Intervention}

The educational packet included (1) written materials about CRC screening from the Centers for Disease Control and Prevention's Screen for Life program, (2) a DVD and booklet about CRC screening from the American Cancer Society, (3) a FIT kit and postage-paid return envelope, (4) a magnet encouraging CRC screening, (5) a CRC screening preference form, and (6) a survey about these materials, called the Educational Assessment Survey, and a postage-paid return envelope. This questionnaire was developed by the PI (BTL) and contained questions about whether the subject read the materials, understood the materials, and whether he or she applied them to their decisions about screening. A similar series of questions were asked about the subject's perceptions of the DVD, as were questions about the patient's attitudes toward, readiness for, and barriers to CRC screening. The Clearview ULTRA FOB FIT (Inverness Medical Professional Diagnostics, Princeton, $\mathrm{NJ}$ ) was chosen because immunochemical tests have better sensitivity and specificity than conventional guaiac tests for detection of cancers and adenomas, ${ }^{23-25}$ and single-use immunochemical tests are superior to single-use guaiac tests ${ }^{26,27}$; it is a Clinical Laboratory Improvement Amendments waived test that could be used by primary care offices and safety net clinics without access to spe- cialized pathology services, and simulation models indicate that an annual FIT is as effective as colonoscopy every 10 years for the outcome of life-years gained compared with no screening. ${ }^{28}$ Subjects could return the FIT to the investigators and their results were mailed to them and their physician. If their test was positive, they were advised that the next step should be a colonoscopy. Subjects also completed a CRC screening preference form to indicate which test they preferred by using a check box. The choices were "take-home hemoccult cards (you can use the FIT kit provided if you like)"; "flexible sigmoidoscopy"; "colonoscopy"; "barium enema"; "unsure which test I want (would like to discuss with my doctor)"; and "I am not ready to make a decision."

One group received the educational packet and FIT only, and the other group received these materials plus a telephone reminder (described below). The educational mailings were sent between April 7, 2009, and May 7, 2010.

\section{Telephone Calls to Encourage Screening}

Telephone calls were made by the study team to those patients randomized to the telephone intervention group 2 to 4 weeks after mailing the educational materials. These were structured to (1) assess the subject's knowledge of CRC and CRC cancer screening, (2) assess the subject's perceptions of previous screening for CRC, (3) provide the subject with basic knowledge regarding CRC and CRC screening, (4) assess the subject's willingness to undergo CRC testing, including determination of major barriers, (5) facilitate the subject's preferred screening test, and (6) provide supportive feedback, no matter what the subject decides. The script was written by the PI (BTL), and 3 research assistants called subjects up to 8 times at various times of day and evening to complete the calls.

\section{Data Analysis}

Means and frequencies were calculated for all variables using SAS version 9.1.3 (SAS Institute, Cary, NC). For some results, variables were categorized for ease of understanding. For the questions relating to attitudes toward screening, readiness for screening, and barriers to screening, a combined variable for each domain was created by averaging the overall scores for the 14 attitude questions, the 6 readiness questions, and the 15 barrier questions. Individual scores were reversed whenever necessary 
and there was no imputation. Difference scores for the mean score for each domain at follow-up minus baseline were calculated. The Wilcoxon signed rank test was used to test whether these differences were significant. A one-sample binomial exact test was used to compare the increase in screening rates with the sample of Iowa Medicare beneficiaries.

\section{Results}

A total of 8372 invitations were mailed to potential subjects from the 16 practices and 2008 subjects (24\%) returned the baseline survey. Of those returned, 838 (42\%) were eligible for CRC screening based on their responses to questions about past CRC screening. However, 88 did not return a signed an informed consent form (despite reminder calls) and 7 were ineligible for other reasons. Thus, of those who were eligible, a total of 743 subjects (89\%) enrolled in the study (completed a baseline questionnaire and signed an informed consent document), and a total of 373 individuals were assigned randomly to the educational mailing plus FIT groups. These 373 subjects included 186 who received mailed education and FIT and 187 who received mailed education, a FIT, and a telephone reminder.

Table 1 summarizes the demographic characteristics of those randomized to the 2 educational groups who responded to the baseline survey. The mean age was 61.2 years (standard deviation, 6.7 years) and 52\% were women. Most were married and white, and more than $60 \%$ had some college education or higher. Nearly two thirds had private medical insurance. Forty percent had incomes less than $\$ 40,000$ per year.

Table 2 shows the summary of the baseline survey for those in the educational intervention groups. Nearly half of the subjects were men and nearly two-thirds of the subjects had a male physician. Family history of colon cancer in an immediate or more distant family member was present in slightly more than $10 \%$ of the subjects for each family history category. Nearly two thirds stated that a physician or nurse had discussed having a test for CRC, with $54 \%$ stating that they had been told to undergo cancer screening (with the explanation that "Screening is to detect possible problems before you have symptoms.") Only 10\% stated they had been advised to have CRC testing because of symptoms. The most commonly recommended
Table 1. Demographic Summary of Subjects $(n=373)$

\begin{tabular}{lc}
\hline Variables & Percentage or Mean \\
\hline Age (mean years \pm SD) & $61.2 \pm 6.7$ \\
Sex & \\
$\quad$ Female & 51.7 \\
$\quad$ Male & 48.3 \\
Marital status & \\
Single & 14.3 \\
Married & 78.2 \\
Widowed & 7.5 \\
Ethnicity & \\
Hispanic & 0.8 \\
Race & \\
White & 99.2 \\
Black & 0.5 \\
Asian & 0.3 \\
Educational level & \\
High school or less & 38.5 \\
Some college or higher & 61.5 \\
Insurance status & \\
Private & 65.2 \\
Medicare & 30.3 \\
None & \\
Annual income & \\
$\quad$ \$40,000 to $<\$ 80,000$ & \\
$\geq \$ 80,000$ & \\
& \\
&
\end{tabular}

tests were colonoscopy (49\%) and fecal occult blood test $(33 \%)$. Subjects generally felt very or extremely satisfied with their doctor's discussions of screening importance (73\%), but were less satisfied with their doctor's discussions of screening options (60\%). Seventy-five percent were very or extremely comfortable asking their doctor questions about CRC screening.

Table 3 shows the distributions of subject responses to questions about attitudes toward, readiness for, and barriers to screening at baseline. The biggest barrier was that the test was not covered by insurance or the copayment was too high $(25 \%$ marked 1 of the 2 highest responses on a scale ranging from 0 [not a factor] to 5 [strong factor]). The next strongest barriers were reporting that the physician had not recommended CRC screening $(23 \%)$ or that the physician had not discussed CRC screening (22\%). Relatively small percentages reported that the following reasons were strong factors preventing screening: (1) the "test would be too painful" (7\%), embarrassment (10\%), and being afraid or anxious about the test $(15 \%)$. With 
Table 2. Summary of Baseline Survey for Those Assigned to Educational Intervention $(n=373)$

\begin{tabular}{|c|c|}
\hline Subject and Physician Characteristics & Percentage \\
\hline Male patient sex & 48.3 \\
\hline Male physician sex & 63.5 \\
\hline \multicolumn{2}{|l|}{ Family history } \\
\hline Immediate family member & 12.4 \\
\hline More distant relative & 11.4 \\
\hline $\begin{array}{l}\text { Physician or nurse ever discussed having a } \\
\text { test for CRC }\end{array}$ & 64.2 \\
\hline $\begin{array}{l}\text { Physician or nurse ever recommended CRC } \\
\text { screening }\end{array}$ & 53.8 \\
\hline $\begin{array}{l}\text { Physician ever recommended a test for } \\
\text { CRC because you had symptoms }\end{array}$ & 10.0 \\
\hline $\begin{array}{l}\text { My doctor has discussed CRC screening } \\
\text { with me }\end{array}$ & 46.1 \\
\hline \multicolumn{2}{|l|}{ Tests recommended by physician $(n=290)$} \\
\hline Colonoscopy & 48.8 \\
\hline Fecal occult blood test $(\times 3)$ & 33.1 \\
\hline Flexible sigmoidoscopy & 14.2 \\
\hline Barium enema & 12.3 \\
\hline Fecal immunochemical test & 10.0 \\
\hline \multicolumn{2}{|l|}{$\begin{array}{l}\text { Quality of CRC screening discussions } \\
\qquad(\mathrm{n}=237)^{*}\end{array}$} \\
\hline $\begin{array}{l}\text { Comfort with asking your doctor } \\
\text { questions about CRC screening }\end{array}$ & 75.5 \\
\hline $\begin{array}{l}\text { Satisfaction with doctor's discussions of } \\
\text { screening importance }\end{array}$ & 73.3 \\
\hline Input into the screening decision & 67.2 \\
\hline $\begin{array}{l}\text { Satisfaction with doctor's discussion of } \\
\text { screening options }\end{array}$ & 60.3 \\
\hline
\end{tabular}

*Responses were provided as "very" or "extremely." CRC, colorectal cancer.

respect to readiness for screening, although $77 \%$ felt very confident that they could be screened (rating this item an 8, 9, or 10 on a scale from 0 [not at all confident] to 10 [very confident]), and nearly two thirds (64\%) rated importance of CRC screening for them with an 8,9 , or 10 , only $40 \%$ felt that they had a strong likelihood of being tested for CRC within the next 6 months and only $37 \%$ felt that they would bring up CRC screening at their next visit.

\section{Perceptions of Educational Materials}

Ninety-three educational surveys (50.0\%) were returned from group 3 and 138 (73.8\%) from group $4(P<.0001)$. Eighty-two percent reported reading at least $75 \%$ or more of the written materials, $91 \%$ understood at least $75 \%$ of the written materials, $95 \%$ felt that the amount of the written materials was just right, and $57 \%$ stated the written materials helped them decide which test to have. With respect to the DVD, $67 \%$ viewed at least $75 \%$ of the DVD, $94 \%$ stated they understood at least $75 \%$ of the material, $96 \%$ stated that the amount of material was just right, and $61 \%$ felt that the DVD helped them decide which test to have.

\section{Changes in Attitudes, Readiness, and Barriers}

Table 4 shows the mean scores at baseline and at follow-up (after the educational materials were received, read, and viewed) for attitude toward, readiness for, and barriers to screening. Attitudes toward and readiness for screening improved significantly between baseline and follow-up (Wilcoxon signed rank, $P<.0001$ for both comparisons). Barriers to testing were significantly lower after the educational intervention (Wilcoxon signed rank, $P=.0342$ ). Mean barrier scores were quite low at both time points, indicating that subjects did not perceive significant barriers to CRC screening.

\section{Return of FIT}

For the primary outcome of return of the FIT, there was no difference between the groups (45.2\% from those receiving educational materials and FIT and $48.7 \%$ from those receiving the additional telephone call; $P=.498, \chi^{2}$ test; Figure 1$)$. This was a large clinical and statistically significant increase when compared with rates for Medicare beneficiaries in Iowa $(P<.0001$ for each group individually and overall, one-sample binomial exact test). (Medicare claims data for Iowa in the calendar year July 1, 2009, to June 30, 2010, showed $4.3 \%$ of 271,192 beneficiaries were screened with a fecal occult blood test in the past year.)

Older age was associated with a higher FIT return rate $(55.7 \%$ for those aged $\geq 65$ and $43.5 \%$ for those $<65$ years; $P=.033$ ). Older age was associated with higher FIT return rates in the group that did not receive a telephone call, but not in the group that did. There were no significant associations with FIT return rates and marital status, income levels, and medical insurance status.

\section{Discussion}

Educational materials accompanied by an easy-toreturn FIT mailed to these rural patients overdue for CRC screening resulted in significant increases in screening rates using the FIT. Older patients 
Table 3. Attitudes, Readiness, and Barriers to Screening at Baseline

\begin{tabular}{|c|c|c|c|}
\hline \multirow{2}{*}{$\begin{array}{l}\text { Attitudes Toward Screening }(\mathrm{n}=319) \\
\text { Sample items* }\end{array}$} & \multicolumn{3}{|c|}{ Category (\%) } \\
\hline & 1 (Strongly Disagree) & $2-4$ & 5 (Strongly Agree) \\
\hline $\begin{array}{l}\text { I really think I should try to be screened } \\
\text { for CRC in the next } 6 \text { months. }\end{array}$ & 3 & 73 & 25 \\
\hline $\begin{array}{l}\text { I have been thinking about whether I } \\
\text { will be able to be screened for CRC. }\end{array}$ & 13 & 79 & 9 \\
\hline $\begin{array}{l}\text { I have had CRC screening in the past } \\
\text { and I plan to continue. }\end{array}$ & 22 & 70 & 8 \\
\hline $\begin{array}{l}\text { I am aware of the importance of regular } \\
\text { screening for CRC, but I can't do it } \\
\text { right now. }\end{array}$ & 15 & 80 & 4 \\
\hline $\begin{array}{l}\text { I have set up a day and a time to be } \\
\text { screened within the next } 2 \text { months. }\end{array}$ & 46 & 51 & 3 \\
\hline $\begin{array}{l}\text { As far as I am concerned, I don't need } \\
\text { CRC screening. }\end{array}$ & 25 & 74 & 2 \\
\hline $\begin{array}{l}\text { I have not been screened and right now } \\
\text { I don't care. }\end{array}$ & 38 & 60 & 2 \\
\hline $\begin{array}{l}\text { I don't have the time or energy to be } \\
\text { screened for CRC right now. }\end{array}$ & 33 & 65 & 2 \\
\hline $\begin{array}{l}\text { I could be screened for CRC, but I } \\
\text { don't plan to. }\end{array}$ & 24 & 75 & 1 \\
\hline Readiness for CRC screening $^{\dagger}(\mathrm{n}=336)$ & 0-2 (Not Ready) & $3-7$ & 8-10 (Very or Definitely Ready) \\
\hline Confidence in ability to be screened & 4.8 & 18.3 & 77.0 \\
\hline Importance of CRC screening for you & 5.7 & 29.9 & 64.4 \\
\hline Readiness for CRC screening & 6.9 & 29.7 & 63.4 \\
\hline Interest in CRC screening & 8.6 & 36.9 & 54.5 \\
\hline $\begin{array}{l}\text { Likelihood of being tested in next } 6 \\
\text { months }\end{array}$ & 20.9 & 38.7 & 40.5 \\
\hline $\begin{array}{l}\text { Likelihood of bringing up CRC } \\
\text { screening at next visit }\end{array}$ & 20.2 & 42.6 & 37.2 \\
\hline Barriers to screening $(\mathrm{n}=298)$ & 0 or 1 (Not a Factor) & 2 or 3 & 4 or 5 (Strong Factor) \\
\hline $\begin{array}{l}\text { Not covered by insurance/copayment is } \\
\text { too high }\end{array}$ & 58.8 & 16.3 & 24.8 \\
\hline Physician has not recommended & 57.2 & 19.9 & 23.0 \\
\hline Physician has not discussed & 57.8 & 20.6 & 21.6 \\
\hline Afraid or anxious about the test & 51.8 & 32.9 & 15.3 \\
\hline I am too busy & 62.1 & 24.3 & 13.6 \\
\hline $\begin{array}{l}\text { I am confused about all of the options } \\
\text { available }\end{array}$ & 65.2 & 22.8 & 12.0 \\
\hline $\mathrm{I}$ am low risk for CRC & 60.6 & 28.9 & 10.6 \\
\hline Too embarrassing & 65.8 & 23.8 & 10.4 \\
\hline No medical insurance & 87.7 & 3.3 & 9.6 \\
\hline Test requires too much time & 66.7 & 24.8 & 8.6 \\
\hline Test will be too painful & 73.8 & 18.9 & 7.3 \\
\hline Test is difficult to schedule & 78.0 & 16.7 & 5.3 \\
\hline Test is not available in my area & 91.9 & 6.8 & 1.4 \\
\hline
\end{tabular}

*Total of 14 sample items.

${ }^{\dagger} 0=$ not at all likely or not interested, important, confident, ready, etc.; $10=$ definitely or very interested, important, confident, ready, etc. CRC, colorectal cancer.

were more likely to return the FIT. The FIT used was a sensitive, single-sample test easily collected in the privacy of the patient's home and returned to the investigators. Receipt of educational materials in print and DVD format was associated with sig- nificant improvements in attitudes toward screening and readiness for screening, and decreased barriers to screening. All subjects received a FIT; there was no statistically significant difference in FIT return rates between those who received the edu- 
Table 4. Comparison of Mean Attitudes, Readiness, and Barriers Scores from Baseline to Follow-up

\begin{tabular}{lcccr}
\hline Domain & Mean at Baseline & Mean at Follow-Up & Mean Difference (Follow-Up Minus Baseline) & $P^{*}$ \\
\hline Attitudes $^{\dagger}$ & 3.30 & 3.55 & 0.22 & $<.0001$ \\
Readiness $^{\ddagger}$ & 7.14 & 7.82 & 0.60 & $<.0001$ \\
Barriers $^{\S}$ & 1.23 & 1.10 & -0.18 & .0342 \\
\hline
\end{tabular}

${ }^{*}$ Wilcoxon signed rank test.

${ }^{\dagger}$ Subjects chose a value from 1 (unfavorable attitude) to 5 (extremely favorable attitude) for 14 questions.

‡Subjects chose a value from 0 (not ready) to 10 (definitely ready) for 6 questions.

${ }^{\S}$ Subjects chose a value from 0 (no barrier) to 5 (major barrier) for 15 questions.

cational materials versus those who received educational materials plus a scripted telephone educational and reminder phone call $(45.2 \%$ vs $48.7 \%$; $P=.498)$. Though the scripted telephone call did not improve FIT return rates, it seemed to improve the rate of return of the questionnaire assessing the educational materials $(74 \%$ for those receiving the telephone reminder vs $50 \%$ for those receiving educational materials alone; $P<.0001$ ). The 2 greatest barriers to screening at baseline were lack of insurance and lack of physician recommendation.

The rates of FIT return of $45 \%$ to $49 \%$ that we found after our educational reminder were similar or higher than those found in other studies. Myers et $\mathrm{al}^{29}$ randomized 1546 primary care patients due for CRC screening at a single university medical practice to 1 of 4 groups: usual care (no mailed materials); standard mailed education plus FIT; mailed tailored intervention, FIT, plus reminder letter; and mailed tailored intervention, FIT, and a telephone reminder. Rates of any CRC testing 24 months after randomization were $33 \%$ in the con- trol group, and $44 \%$ to $46 \%$ in the intervention groups. All intervention groups were significantly higher than the control groups, but not different from each other. ${ }^{29}$ Thus, Myers et $\mathrm{al}^{29}$ found rates of screening similar to ours using a mailed intervention that included a FIT. In addition, they also found no improvement in rates with a reminder telephone call. ${ }^{29}$ More research needs to be done about the effect of reminder calls because automated reminders improved CRC screening rates among older patients in a managed care setting (22.5\% screening in the automated call group and $16.0 \%$ in the usual care group), ${ }^{30}$ but our findings did not show that older patients receiving a telephone reminder had higher FIT return rates. Mailed reminder letters improved CRC screening rates among patients overdue for screening to $22 \%$ among 131,860 health plan members of a large health care plan in Hawaii. ${ }^{31}$ A study that randomized all 21,860 patients overdue for CRC screening from 14 ambulatory practices in the Harvard Vanguard Medical Associates system to mailed education versus no mailed education; the researchers

Figure 1. Fecal Immunochemical Test (FIT) Return Rate. All patients were initially unscreened. There was no difference between these two groups $(P=.498$, chi-square test), but there was a significant increase in FIT return in both groups when compared with Medicare beneficiaries in the state of Iowa $(P<.0001$, individually and overall, one-sided binomial exact test).

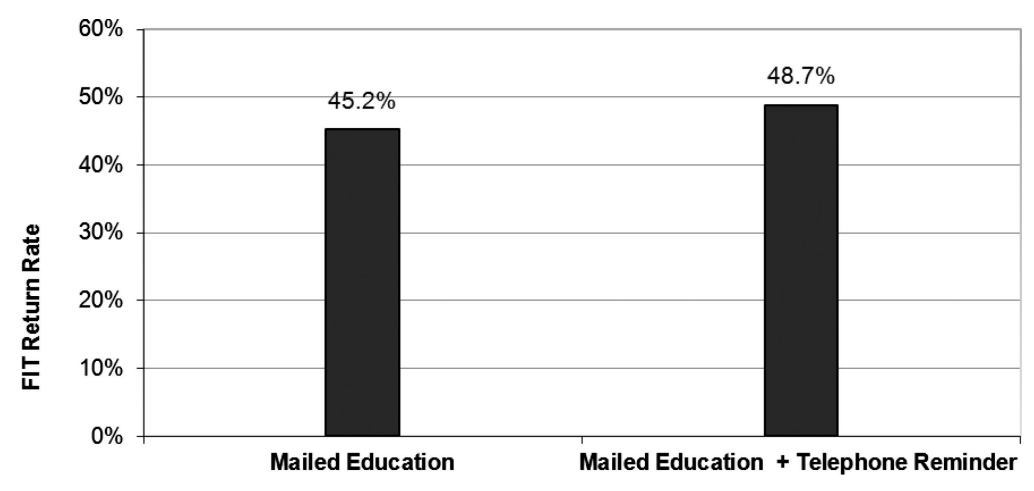


found overall CRC screening rates at follow-up close to the values we found ( $44 \%$ for mailed group vs $38 \%$ for the group that did not receive a mailing; $P<.001) .{ }^{32}$ Interestingly, these researchers did not obtain individual informed consent for their study because their institutional review board felt that the procedures were promoting the Harvard Vanguard Medical Associates standard of care for CRC screening. ${ }^{32}$ A tailored versus a nontailored educational print intervention was compared in a group of individuals who had a first-degree relative with CRC. ${ }^{33}$ There was a small increase in screening for each intervention, with no significant difference between them (14\% for tailored vs $21 \%$ for nontailored). ${ }^{33}$ Daly et $\mathrm{al}^{34}$ mailed FITs (with very brief educational statements in the cover letter) to eligible patients attending a university family medicine or internal medicine practice and $26 \%$ of individuals completed a FIT. Ling et $\mathrm{al}^{35}$ found that providing enhanced office and patient management led to more than 50\% CRC screening rates among patients due for screening.

This study has several strengths. It was conducted in a real-world setting of patients attending 16 rural family physician practices. The practices were randomly chosen from a sample of 27 practices in counties with median incomes below the average for the state of Iowa. This increased the likelihood of enrolling individuals of low socioeconomic status into the study. The wording on the cover letter to patients was designed to be direct and easily understood, emphasized that everyone older than age 50 should be screened for CRC, and that one does not need symptoms to have CRC. Letters were mailed on the practice letterhead and signed by all the physicians in the respective practices, which hopefully helped lend credibility to the information and indicated the support of their personal physician. The educational materials were nontailored, eliminating significant time and expense in developing a personalized, tailored intervention for each participant. We could not find similar studies in which mailed educational materials were combined with mailed FITs conducted in a rural, statewide, primary care, practice-based research network setting. Given the results of this work and others, it seems clear that providing offices with support for CRC screening leads to improved CRC screening rates. ${ }^{31,35-39}$

Weaknesses include participation bias in that individuals with no interest in CRC screening likely would not agree to participate. In addition, patients were recruited from family physician offices and thus had access to medical care. These results may not be applicable to individuals who do not have a primary care physician. Because CRC screening is not controversial and saves lives, future studies should attempt to conduct and evaluate interventions to improve CRC screening without obtaining individual informed consent so that a more representative sample from family physician offices is obtained. Although attitudes toward and readiness for CRC screening improved and barriers decreased, we have an incomplete picture of the effect of the mailed education and scripted telephone reminder because we received educational surveys from only $62 \%$ of the participants. Sending out a reminder letter to subjects who failed to return their follow-up survey might have improved this rate. In addition, although we have some evidence that improved patient attitudes led to return of the FIT, we could not be certain of this. If a similar intervention is used in other settings, it would almost certainly include an educational component. Therefore, we did not include a comparison group that received an FIT with no educational materials. We do not know if providing postage-paid return envelopes increased FIT return because all patients received postage-paid envelopes. We also do not know the effect on return rates of the small incentive provided in this study. We wished to test the strongest possible intervention that had a good chance of working and decided to provide patients with all information and materials needed to successfully return the FIT if they so desired. Another article will present the final results of detailed chart reviews conducted to ascertain CRC screening by any one of the modalities recommended by current screening guidelines. ${ }^{5-7,27}$

\section{Conclusion}

It has been estimated that $50 \%$ to $80 \%$ of CRC cases could be prevented with appropriate screening. ${ }^{1-4}$ Screening rates are lower in those who are socioeconomically disadvantaged and in rural populations. Mailed, nontailored educational materials, along with a FIT, led to nearly half of patients due for screening being screened in this rural population. A key feature of this intervention was the inclusion of the FIT with the mailed educational materials. Organizations and practices seeking to 
improve screening rates should consider incorporating postage-paid returnable FITs along with mailed educational materials to patients due for CRC screening. The nation's health care system should provide coverage for CRC screening that includes appropriate follow-up testing. Nearly 1 in 4 patients found lack of insurance or a high copayment to be a significant barrier to screening and, similarly, nearly 1 in 4 perceived lack of physician recommendation to be a strong barrier to screening. Some providers may need to be educated about the importance of offering CRC screening.

\section{References}

1. Subramanian S, Bobashev G, Morris RJ. Modeling the cost-effectiveness of colorectal cancer screening: policy guidance based on patient preferences and compliance. Cancer Epidemiol Biomarkers Prev 2009;18(7):1971-8.

2. Vogelaar I, van Ballegooijen M, Schrag D, et al. How much can current interventions reduce colorectal cancer mortality in the U.S.? Mortality projections for scenarios of risk-factor modification, screening, and treatment. Cancer 2006;107(7): 1624-33.

3. National Center for Chronic Disease Prevention and Health Promotion, Division of Cancer Prevention and Control, Centers for Disease Control and Prevention. CDC Vital Signs. Colorectal cancer: 1 in 3 adults are not being screened. Available at www. cdc.gov/VitalSigns/pdf/2011-07-vitalsigns.pdf. Updated 2011. Accessed July 13, 2011.

4. National Cancer Institute. Colorectal cancer screening (PDQ). Available at http://www.cancer. gov/cancertopics/pdq/screening/colorectal/Health Professional. Accessed July 13, 2011.

5. U.S. Preventive Services Task Force. Screening for colorectal cancer: U.S. Preventive Services Task Force recommendation statement. Ann Intern Med. 2008;149(9):627-37.

6. Levin B, Lieberman DA, McFarland B, et al. Screening and surveillance for the early detection of colorectal cancer and adenomatous polyps, 2008: a joint guideline from the American Cancer Society, the US Multi-Society Task Force on Colorectal Cancer, and the American College of Radiology. Gastroenterology 2008;134(5):1570-95.

7. Smith RA, Cokkinides V, Brooks D, Saslow D, Brawley OW. Cancer screening in the United States, 2010: a review of current American Cancer Society guidelines and issues in cancer screening. Cancer J Clin 2010;60(2):99-119.

8. Yeazel M, Church TR, Jones RM, et al. Colorectal cancer screening adherence in a general population. Cancer Epidemiol Biomarkers Prev 2004;13(4): 654-7.
9. Levy BT, Dawson J, Hartz AJ, James PA. Colorectal cancer testing among patients cared for by Iowa family physicians. Am J Prev Med 2006;31(3):193201.

10. Crawford ND, Jones CP, Richardson LC. Understanding racial and ethnic disparities in colorectal cancer screening: Behavioral Risk Factor Surveillance System, 2002 and 2004. Ethn Dis 2010;20(4): 359-65.

11. Stone EG, Morton SC, Hulscher ME, et al. Interventions that increase use of adult immunization and cancer screening services: a meta-analysis. Ann Intern Med 2002;136(9):641-51.

12. Hibbard JH, Stockard J, Mahoney ER, Tusler M. Development of the Patient Activation Measure (PAM): conceptualizing and measuring activation in patients and consumers. Health Serv Res 2004;39(4 Pt 1):1005-26.

13. Hollon MF. Direct-to-consumer advertising: a haphazard approach to health promotion. JAMA 2005; 293(16):2030-3.

14. Kravitz RL, Epstein RM, Feldman MD, et al. Influence of patients' requests for direct-to-consumer advertised antidepressants: a randomized controlled trial. JAMA 2005;293(16):1995-2002.

15. Wolf RL, Basch CE, Brouse CH, Shmukler C, Shea $\mathrm{S}$. Patient preferences and adherence to colorectal cancer screening in an urban population. Am J Public Health 2006;96(5):809-11.

16. Almog R, Ezra G, Lavi I, Rennert G, Hagoel L. The public prefers fecal occult blood test over colonoscopy for colorectal cancer screening. Eur J Cancer Prev 2008;17(5):430-7.

17. DeBourcy AC, Lichtenberger S, Felton S, Butterfield KT, Ahnen DJ, Denberg TD. Communitybased preferences for stool cards versus colonoscopy in colorectal cancer screening. J Gen Intern Med 2008;23(2):169-74.

18. Collaborative Institutional Training Initiative [Homepage]. Available at https://www.citiprogram. org/. Accessed November 5, 2010.

19. Dillman DA. Mail and Internet surveys: the tailored design method. 2nd ed. Hoboken, NJ: John Wiley \& Sons; 2007.

20. Daly JM, Xu Y, Ely JW, Levy BT. A randomized colorectal cancer screening intervention trial in the Iowa Research Network (IRENE): study recruitment methods and baseline results. J Am Board Fam Med 2011;25:63-72.

21. Levy BT, Nordin T, Sinift S, Rosenbaum M, James PA. Why hasn't this patient been screened for colon cancer? An Iowa Research Network study. J Am Board Fam Med 2007;20(5):458-68.

22. Vernon SW, Myers RE, Tilley BC. Development and validation of an instrument to measure factors related to colorectal cancer screening adherence. Cancer Epidemiol Biomarkers Prev 1997;6(10):825-32. 
23. Dancourt V, Lejeune C, Lepage C, Gailliard MC, Meny B, Faivre J. Immunochemical faecal occult blood tests are superior to guaiac-based tests for the detection of colorectal neoplasms. Eur J Cancer 2008;44(15):2254-8.

24. van Rossum LG, van Rijn AF, Laheij RJ, et al. Random comparison of guaiac and immunochemical fecal occult blood tests for colorectal cancer in a screening population. Gastroenterology 2008; 135(1):82-90.

25. Smith A, Young GP, Cole SR, Bampton P. Comparison of a brush-sampling fecal immunochemical test for hemoglobin with a sensitive guaiac-based fecal occult blood test in detection of colorectal neoplasia. Cancer 2006;107(9):2152-9.

26. Quintero E, Gimeno-Garcia AZ, Parra-Blanco A, et al. One-time screening with an immunochromatographic occult blood test predicts the detection of advanced adenoma and colorectal cancer in the average-risk population. Can J Gastroenterol 2005; 19(Suppl B):21B.

27. Whitlock EP, Lin JS, Liles E, Beil TL, Fu R. Screening for colorectal cancer: a targeted, updated systematic review for the U.S. Preventive Services Task Force. Ann Intern Med 2008;149(9): 638-58.

28. Zauber AG, Lansdorp-Vogelaar I, Knudsen AB, Wilschut J, van Ballegooijen M, Kuntz KM. Evaluating test strategies for colorectal cancer screening: a decision analysis for the U.S. Preventive Services Task Force. Ann Intern Med 2008;149(9):659-69.

29. Myers RE, Sifri R, Hyslop T, et al. A randomized controlled trial of the impact of targeted and tailored interventions on colorectal cancer screening. Cancer 2007;110(9):2083-91.

30. Mosen DM, Feldstein AC, Perrin N, et al. Automated telephone calls improved completion of fecal occult blood testing. Med Care 2010;48(7):604-10.
31. Zhu J, Davis J, Taira DA, Yamashita M. Screening rates and characteristics of health plan members who respond to screening reminders. Prev Chronic Dis 2006;3(2):A56.

32. Sequist TD, Zaslavsky AM, Marshall R, Fletcher RH, Ayanian JZ. Patient and physician reminders to promote colorectal cancer screening: a randomized controlled trial. Arch Intern Med 2009;169(4):364-71.

33. Rawl SM, Champion VL, Scott LL, et al. A randomized trial of two print interventions to increase colon cancer screening among first-degree relatives. $\mathrm{Pa}-$ tient Educ Couns 2008;71(2):215-27.

34. Daly JM, Levy BT, Merchant ML, Wilbur J. Mailed fecal-immunochemical test for colon cancer screening. J Community Health 2010;35(3):235-9.

35. Ling BS, Schoen RE, Trauth JM, et al. Physicians encouraging colorectal screening: a randomized controlled trial of enhanced office and patient management on compliance with colorectal cancer screening. Arch Intern Med 2009;169(1):47-55.

36. Wei EK, Ryan CT, Dietrich AJ, Colditz GA. Improving colorectal cancer screening by targeting office systems in primary care practices: disseminating research results into clinical practice. Arch Intern Med 2005;165(6):661-6.

37. Ornstein S, Nemeth LS, Jenkins RG, Nietert PJ. Colorectal cancer screening in primary care: translating research into practice. Med Care 2010;48(10): 900-6.

38. Nease DE Jr, Ruffin MT, Klinkman MS, Jimbo M, Braun TM, Underwood JM. Impact of a generalizable reminder system on colorectal cancer screening in diverse primary care practices: a report from the prompting and reminding at encounters for prevention project. Med Care 2008;46(9 Suppl 1):S68-73.

39. Klabunde C, Lanier D, Breslau ES, et al. Improving colorectal cancer screening in primary care practice: innovative strategies and future directions. J Gen Intern Med 2007;22:1195-205. 